\title{
Returning to Sport Following COVID-19: Considerations for Heat Acclimatization in Secondary School Athletics
}

\author{
William M. Adams ${ }^{1} \mathbb{D}$. Julien D. Périard ${ }^{2}$
}

Published online: 13 June 2020

C) Springer Nature Switzerland AG 2020

The cataclysmic events that have taken place across the globe as a result of the COVID-19 pandemic have infiltrated every aspect of society, including sport. As many places around the world are either beginning to observe or are on a downward descent of "flattening of the curve", local, regional/state and national leaders have initiated steps to lift various stay-at-home orders and resume normal activities. With the recommencement of sanctioned athletic events over the upcoming summer months within the Northern Hemisphere, increased caution must be taken by clinicians, administrators, coaches and other stakeholders to ensure that proper procedures are in place to reduce the risk of injury, particularly at the secondary school level. The prolonged dormancy of secondary school student-athletes as a result of the current global pandemic, in combination with extreme heat observed during the summer months, also places these individuals at increased risk of exertional heat stroke (EHS), thus necessitating increased scrutiny toward optimizing EHS-related risk-reduction strategies.

Heat acclimatization, repeated bouts of exercise in a hot environment eliciting an increase of whole-body body temperature and profuse sweating, permits a series of thermoregulatory and cardiovascular adaptations that improve one's tolerance to exercise in the heat [1]. Within team-based sports (e.g. soccer, cross country, and American Football), current recommendations [2,3] encourage a 10-14 day gradual progression to full activity in outoor environments that takes into consideration the duration and volume of activity, as well as protective equipment that is worn in respective

William M. Adams

wmadams@uncg.edu

1 Hydration, Environment, and Thermal Stress Lab, Department of Kinesiology, University of North Carolina at Greensboro, 1408 Walker Avenue, 237L Coleman Building, Greensboro, NC 27455, USA

2 Research Institute for Sport and Exercise, University of Canberra, Bruce, ACT 2612, Australia sports to mitigate the risk of EHS. Recent evidence shows that when these recommendations are mandated at the state/ organizational level for secondary school athletics, a risk reduction rate of $55 \%$ is observed for exertional heat illness [4].

Of particular concern surrounding the resumption of secondary school athletics is the overall risk profile for student-athletes returning to sport. It can be presumed that the extensive societal restrictions placed on individuals to aid in controlling the COVID-19 pandemic will result in an extended period time of potential inactivity and limited passive heat exposure amongst a large number of secondary school student-athletes. Prior literature has found that low physical fitness and being overweight was prevalent in $77 \%$ and $64 \%$ of EHS cases, respectively [5]. Evidence also suggests that the initial 2-3 days of training in a hot environment poses the greatest risk of exertional heat illness [6], hence the early season gradual progression to full activity heat acclimatization recommendation [2, 3]. However, adopting an alternative approach to heat acclimatization within secondary school athletics following the COVID-19 pandemic may be necessary to account for the aforementioned concerns related to the student-athlete EHS risk profile.

Endurance training to enhance cardiovascular fitness provides partial physiological benefits in the realm of heat acclimatization, as evidenced by studies showing that $4-8$ weeks of aerobic-based training in temperate conditions improved physiological (i.e., lower heart rate) and thermoregulatory (i.e., increased sweat rate and decreased rate of rise of internal body temperature) responses, when exposed to a thermally stressful environment $[7,8]$. Prolonging the heat acclimatization period from 10-14 to 17-24 days, with the first 7-10 days focused specifically on improving cardiovascular fitness (i.e., exercise acclimatization), may provide an environment that is conducive to improving the health and safety of student-athletes. Although 7-10 days of endurance and circuit training might only initiate the adaptive process relative to 4-8 weeks of training, it may allow for an easier 


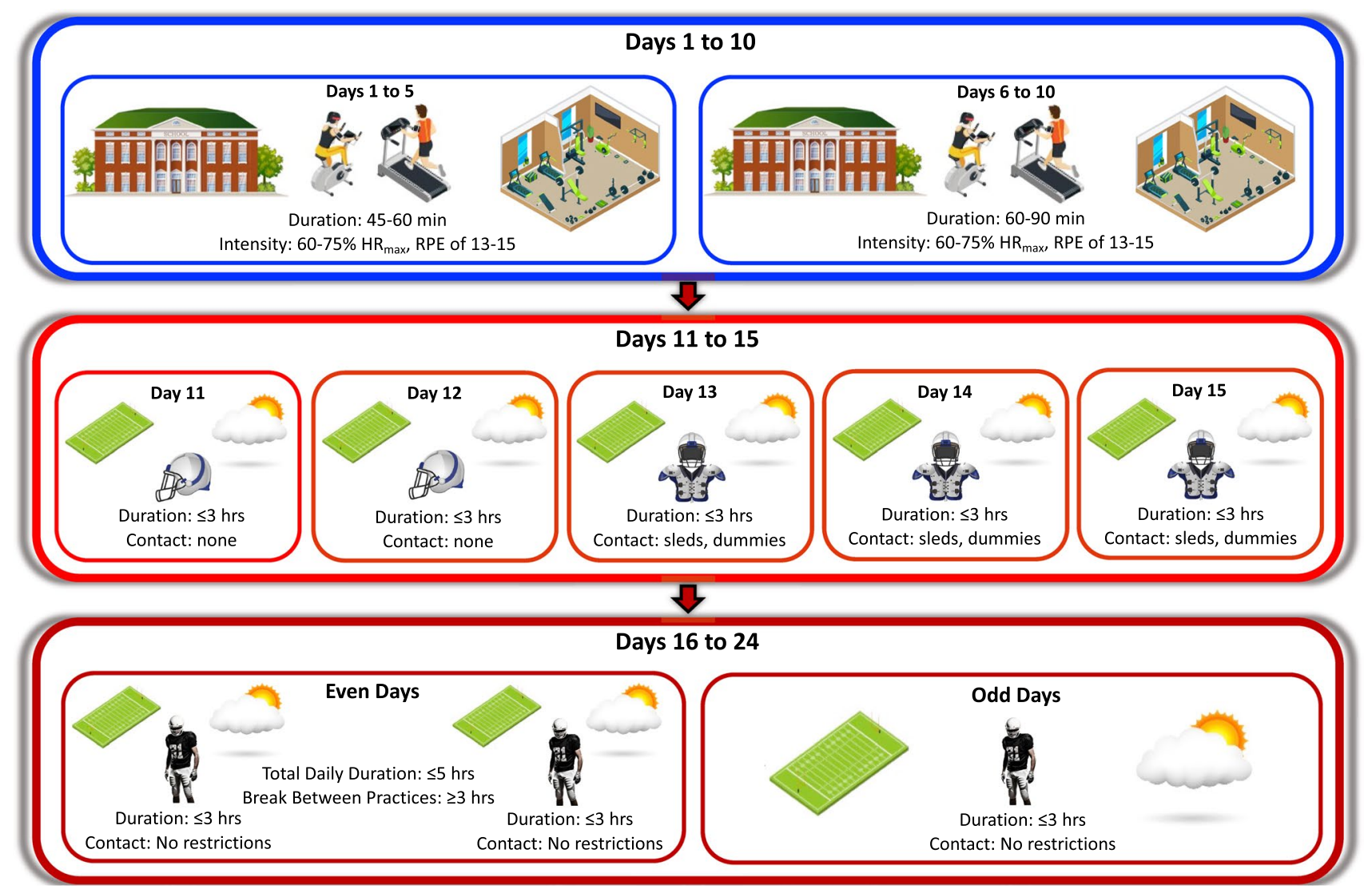

Fig. 1 Modified heat acclimatization guidelines for secondary school sports. Days 1-10 are dedicated to improving aerobic fitness through endurance (e.g. cycling and/or running) and circuit training activities in cool conditions. The volume of training should gradually increase from 45 to 90 min over this period with intensity kept at low to moderate levels. Days 11-24 are dedicated to heat acclimatization. During days 11-15, athletes may not participate in more than 1 practice per day and total practice time may not exceed $3 \mathrm{~h}$. During days 11-12 of heat-acclimatization, in sports requiring helmets or shoulder pads, a helmet should be the only protective equipment permitted. During days $13-15$, only helmets and shoulder pads should be worn. Beginning on day 16 , all protective equipment may be worn and full con- tact may begin. For American Football, contact with blocking sleds and tackling dummies may be initiated on days $13-15$, whereas $100 \%$ live contact drills should begin no earlier than day 16 for full-contact sports. Beginning no earlier than day 16 and continuing through day 24 , double-practice days must be followed by a single-practice day. On a double-practice day, neither practice should exceed $3 \mathrm{~h}$ and a daily maximum of no more than $5 \mathrm{~h}$ of total practice time. The 2 practices should be separated by at least 3 continuous hours in a cool environment. Warm-up, stretching, cool-down, walk-through, conditioning and resistance training are considered practice time. $H R_{\max }$ maximum heart rate, $R P E$ rating of perceived exertion

the secondary school level. Furthermore, taking a more conservative approach to heat acclimatization by extending the duration of this period to focus on improving cardiovascular fitness prior to full heat exposure would allow for a safer transition back to sport for the secondary school student-athlete.

Author Contributions WMA and JDP contributed to the conception, writing, critical revision, and approval of the submitted work.

\section{Compliance with Ethical Standards}

Conflict of interest William Adams has a potential conflict of interest as a recipient of royalties from Springer Nature for a text on exertional position of providing oversight for the education an implementation of the heat acclimatization procedures at 
heat illness for which he is the editor. Julien Périard has no potential conflicts of interest relevant to the content of this article.

Funding No sources of funding were used to assist in the preparation of this article.

\section{References}

1. Périard JD, Racinais S, Sawka MN. Adaptations and mechanisms of human heat acclimation: applications for competitive athletes and sports. Scand J Med Sci Sports. 2015;25:20-38. https://doi. org/10.1111/sms.12408.

2. Casa DJ, Csillan D, Inter-Association Task Force for Preseason Secondary School Athletics Participants, et al. Preseason heat-acclimatization guidelines for secondary school athletics. J Athl Train. 2009;44:332-3. https://doi. org/10.4085/1062-6050-44.3.332.

3. Casa DJ, DeMartini JK, Bergeron MF, et al. National Athletic Trainers' Association position statement: exertional heat illnesses. J Athl Train. 2015;50:986-1000. https://doi. org/10.4085/1062-6050-50.9.07.
4. Kerr ZY, Register-Mihalik JK, Pryor RR, et al. The association between Mandated Preseason Heat Acclimatization Guidelines and Exertional Heat Illness during Preseason High School American Football Practices. Environ Health Perspect. 2019;127:47003. https://doi.org/10.1289/EHP4163.

5. Rav-Acha M, Hadad E, Epstein Y, et al. Fatal exertional heat stroke: a case series. Am J Med Sci. 2004;328:84-7.

6. Cooper ER, Ferrara MS, Casa DJ, et al. Exertional heat illness in American Football Players: when is the risk greatest? J Athl Train. 2016;51:593-600. https://doi.org/10.4085/1062-6050-51.8.08.

7. Ravanelli N, Gagnon D, Imbeault P, et al. A retrospective analysis to determine if exercise training-induced thermoregulatory adaptations are mediated by increased fitness or heat acclimation. Exp Physiol. 2020. https://doi.org/10.1113/EP088385.

8. Avellini BA, Shapiro Y, Fortney SM, et al. Effects on heat tolerance of physical training in water and on land. J Appl Physiol Respir Environ Exerc Physiol. 1982;53:1291-8. https://doi. org/10.1152/jappl.1982.53.5.1291.

9. Adams WM, Scarneo SE, Casa DJ. State-level implementation of health and safety policies to prevent sudden death and catastrophic injuries within secondary school athletics. Orthop J Sports Med. 2017;5:2325967117727262. https://doi.org/10.1177/2325967117 727262 . 